\title{
1. Introduction: Public pharmaceutical expenditure
}

\section{J. Puig-Junoy}

\section{PHARMACEUTICALS AND EFFICIENT HEALTH PRODUCTION}

In the analysis of health care the price of care is often confused with the level of expenditure, particularly so in the analysis of the cost of pharmaceuticals. Pharmaceutical cost containment should never be the exclusive goal of public policies: emphasis on costs without paying attention to the value of the products may lead to inefficient policies. The value of a new pharmaceutical resides in its ability to improve health, not just in its contribution to the decrease or increase of health care costs. Increased spending on health care and pharmaceuticals is therefore compatible with a reduction in their price, if the resulting value increases more than the expenditure.

According to a common cliché, health care spending on pharmaceuticals is excessive in Spain, although the figures do little to endorse this idea, and moreover do not in themselves serve to lay blame or pinpoint inefficiencies. Public and private pharmaceutical spending per capita in Spain is not among the highest in the European Union (EU): it is almost 10 per cent lower than the European average, and lower than the figure for nine of the 15 Member States. The proportion of spending on pharmaceuticals within health care expenditure as a whole stands at around 20 per cent (20.7 per cent in 1997), according to data published by the Organization for Economic Co-operation and Development (OECD). This indicator shows wide variation internationally, from less than 10 per cent in Denmark, Ireland and Switzerland to 26.5 per cent in Hungary and 35 per cent in Bulgaria. The proportion is greater in lower-income countries than in higher income ones.

The allocation of a greater or lesser proportion of the total health expenditure to pharmaceuticals merely indicates that there are different ways of combining resources to produce health care. The superiority of one combination of resources over another can only be established by examining the aggregate results of the resources used on the health status of the population.

The economic cost of the pharmaceuticals for the patient and society as a 
whole is not well represented by the observation of higher or lower pharmaceutical expenditure. The opportunity cost of pharmaceuticals must take into account the benefit they provide, and also the problems that may arise from pharmacological treatment (prescription and medication errors and various types of interaction, incomplete treatment, adverse reactions to pharmaceuticals and bacterial resistance). The degree of suitability of the prescription is an illustration of problems related to the benefits of pharmaceuticals.

\section{INTERPRETING MEASURES OF HEALTH CARE SPENDING ON PHARMACEUTICALS}

The interpretation of the available empirical evidence of the absolute and relative magnitude of pharmaceutical expenditure on an aggregate or macroeconomic level is often prone to the effects of confusing the level of expenditure with the cost or price of care. It is of great value to identify two very important aspects for measuring and interpreting pharmaceutical expenditure.

Firstly, we should review the problems associated with the available empirical evidence in aggregate-level statistical sources for the health system that are used most frequently in the analysis of pharmaceutical expenditure. Secondly, the conditions to be fulfilled by the measures of the relative importance of pharmaceutical spending within health care spending should be clearly established, thus enabling us to observe what type of variation is occurring, and the nature of the underlying explanatory factors that are responsible for the evolution of the observed spending. This would allow valid comparisons between forecast and actual spending.

According to OECD figures, pharmaceutical spending accounted for 22 per cent of Spain's public health care expenditure in 2001. This is considerably more than in a large number of countries, only Portugal (24 per cent in 1997), and Hungary (25.3 per cent) registering higher percentages. Furthermore, this 2001 figure for Spain represented a considerable increase over the figure for 1987 (14.9 per cent). However, at present the proportion is clearly smaller than that observed in Spain at the beginning of the 1970s (34.8 per cent in 1973), and it remained steady from 1979 to 1994 (see Table 1.1).

Yet public pharmaceutical expenditure per capita is lower in Spain than in many OECD countries. In 2001 public spending on pharmaceuticals stood at US\$251 per person, less than in countries such as France (US\$354) Germany (US\$284), Japan (US\$269) and Luxembourg (US\$268 in 2000).

These examples highlight that the interpretation of this relative magnitude, chosen by many authors as an indicator of the exception that Spain constitutes as regards pharmaceutical drug consumption, is questionable at best. This empirical measure is far from representing the combination of pharmaceutical 
and non-pharmaceutical resources adopted by each health system (relative amount of resources or technology) for several reasons. The participation and contribution of the pharmaceutical resource to health production should be evaluated on the basis of data indicating the consumption of factors of production that are not contaminated by the origin of the funding. Thus, for example, cross-national comparisons of public pharmaceutical spending at a particular time are affected by major differences in levels of co-payment (that is, user participation in the funding of pharmaceuticals) between countries (see Table 1.2). The variation over time of the level of co-payment in Spain (a markedly decreasing trend) is bringing about changes in the share of public health expenditure devoted to pharmaceutical spending that do not reflect any rise in relative consumption of the pharmaceutical resource but rather private financing that is not only one of the lowest in the EU but moreover is decreasing.

Given that there is a crossover between public and private pharmaceutical financing in the production of health services (users with coverage who prefer to pay the retail price of the drug to the inconvenience of obtaining the prescription from the public primary care provider; direct-payment prescriptions made out in a private surgery that are subsequently reclassified as prescriptions made out by a public primary care provider), the observation of empirical data on public pharmaceutical spending is not meaningful as an indicator of resource combination in health production. There are more advantages to be had in observing the total pharmaceutical expenditure as compared to the total health expenditure (Table 1.3). If we observe the behaviour of this indicator, we can see that although the Spanish rate is high (20.7 per cent in 1997), nevertheless: (a) it is lower than or on a par with countries such as France, Greece, Hungary, Japan, Portugal and the Czech Republic, although higher than the rest of the OECD countries, and (b) its 1997 value is still slightly lower than its 1980 value.

Cross-national comparisons of pharmaceutical spending are likewise extraordinarily misleading, as the final pharmaceutical expenditure includes taxes and intermediaries' markups, both of which are very different from country to country.

The analysis of the contribution made by increased pharmaceutical spending to the growth in the per capita intensity of health resources suffers from major measurement problems that deprive available indicators of any value. Traditional pharmaceutical price indexes (such as the Laspeyres index, used to calculate the pharmaceutical component of the consumer price index) provide little relevant information in a market in which the introduction of therapeutic innovations is of prime importance; the indexes show an apparent freeze, and sometimes even a steep drop (as in the Spanish case). However, the steady rise in the average price per prescription paints a very different picture.

The rise in the average price of medicines can be attributed to any of 9781845424664 
Table 1.1 Public pharmaceutical expenditure as a percentage of public health expenditure

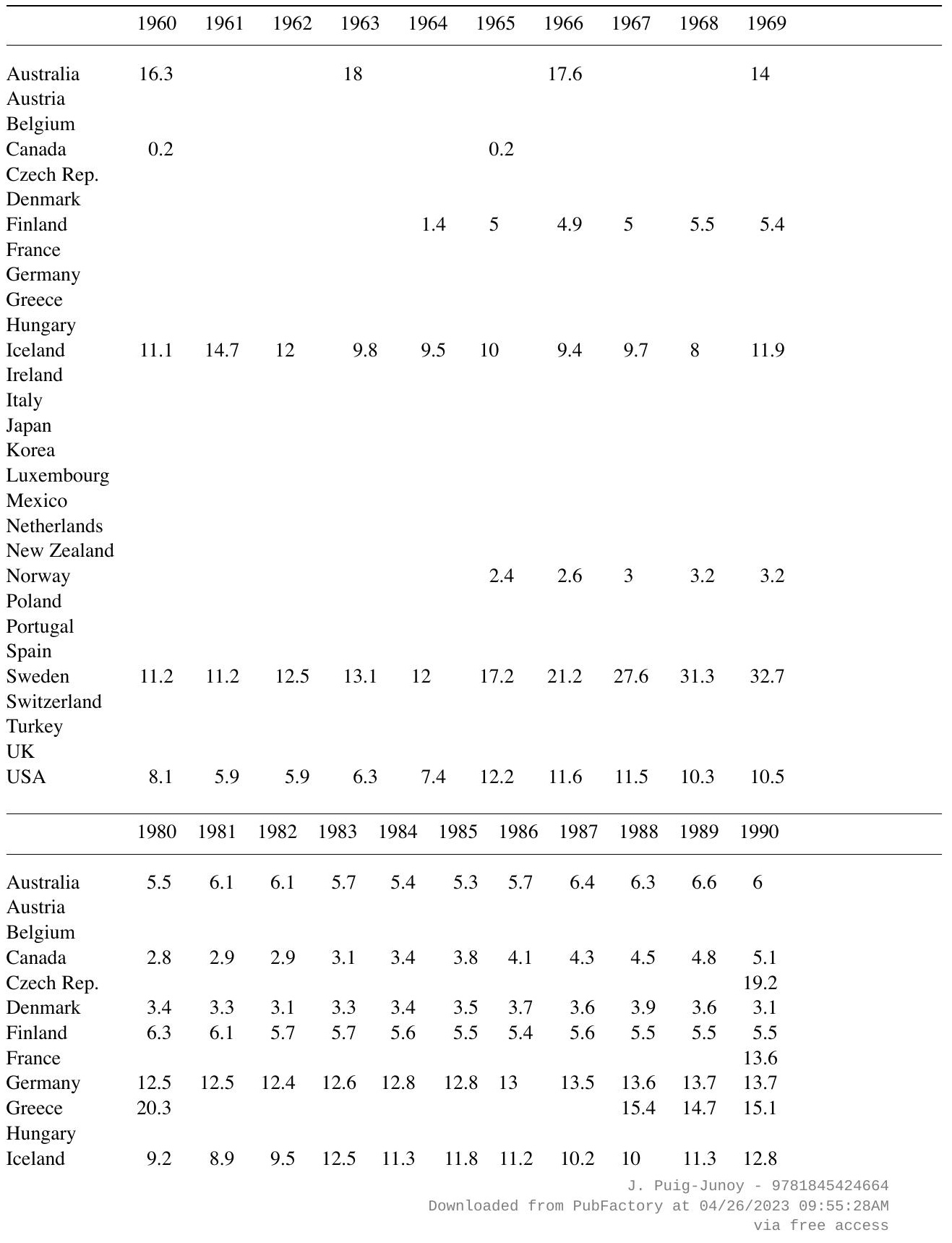




$\begin{array}{lccccccccc}1970 & 1971 & 1972 & 1973 & 1974 & 1975 & 1976 & 1977 & 1978 & 1979 \\ & 12.3 & 11.1 & 11.1 & 10.2 & 7.6 & 6 & 6.3 & 6 & 5.6 \\ & & & & & & & & & \\ 0.3 & 0.5 & 0.6 & 0.8 & 1.1 & 1.7 & 2 & 2.2 & 2.5 & 2.7 \\ & & & & & & & & & \\ 5.8 & 6.6 & 7.2 & 7.2 & 7.5 & 7.1 & 7.1 & 7 & 6.8 & 6.6 \\ 14.1 & 13.5 & 13.4 & 13.1 & 13 & 12.7 & 12.8 & 12.4 & 12.4 & 12.5 \\ 36 & & & & & & & & & \\ 11.2 & 10 & 7.3 & 7.2 & 7.5 & 9.2 & 7.6 & 7.2 & 8.9 & 7.9 \\ 13.6 & & 2.7 & 4.8 & 5.7 & 7.5 & 7.6 & 7.3 & 7 & 6.9\end{array}$

18.5

$\begin{array}{lllll}15.4 & 15.5 & 14.5 & 14.3 & 14\end{array}$

$\begin{array}{rrrrrrrrrr} & & 10.2 & 10 & 9.2 & 8.9 & 8.6 & 8.4 & 8.2 & 7.9 \\ 11.3 & 11.8 & 10.6 & 11 & 10.1 & 10.2 & 11 & 11.2 & 10.6 & 10.3 \\ 3.1 & 3.3 & 3 & 3.1 & 3.4 & 3.4 & 3.3 & 3.3 & 3.4 & 3.6\end{array}$

$\begin{array}{lllll}15.6 & 19.6 & 19.1 & 19.7 & 21.4\end{array}$

$\begin{array}{llllllllll}32.3 & 34 & 33.4 & 34.8 & 29.5 & 27 & 20.6 & 18.8 & 18.9 & 17.7\end{array}$

$\begin{array}{llllllllll}4.8 & 5 & 5.5 & 6.2 & 5.9 & 5.9 & 5.6 & 5.5 & 5.4 & 5.3\end{array}$

$\begin{array}{llllllllll}10 & 9.8 & 9.7 & 9.4 & 10.3 & 8.7 & 9.5 & 10.3 & 10.6 & 10\end{array}$ $\begin{array}{llllllllllll}1991 & 1992 & 1993 & 1994 & 1995 & 1996 & 1997 & 1998 & 1999 & 2000 & 2001 & 2002\end{array}$

$\begin{array}{rrrrrrrrrrrr}6 & 7 & 7.9 & 8.2 & 9.1 & 9.2 & 8.7 & 8.9 & 9.3 & 10.7 & 10.9 & \\ & & & & 11 & 11.3 & 13.6 & 14.8 & 15.5 & 16.2 & 17 & 17.3\end{array}$

$\begin{array}{lllll}10.1 & 9.9 & 10.3 & 11.2 & 11.5\end{array}$

$\begin{array}{rrrrrrrrrrrr}5.3 & 5.7 & 5.9 & 5.9 & 6.4 & 6.4 & 6.6 & 6.9 & 7.3 & 7.8 & 8.2 & 8.4\end{array}$

$\begin{array}{lllllllllll}16.9 & 19.7 & 17.8 & 22.7 & 23.1 & 22.9 & 22.3 & 22.7 & 19.6 & 18.8 & 18.4\end{array}$

$\begin{array}{rllllllllll}4.7 & 5 & 5 & 5.1 & 5.3 & 5.2 & 5.2 & 5.4 & 5.2 & 5.2 & 5.5\end{array}$

$\begin{array}{lllllllllll}5.9 & 6.2 & 7.2 & 8.1 & 8.4 & 8.8 & 9.3 & 9.2 & 9.8 & 10.4 & 10.7\end{array}$

$\begin{array}{lllllllllll}13.8 & 13.8 & 14.1 & 13.8 & 14.2 & 14.3 & 14.8 & 15.4 & 16.4 & 17.4 & 18.2\end{array}$

$\begin{array}{llllllllll}14 & 11.6 & 11.4 & 11.4 & 11.5 & 11.2 & 11.6 & 12.3 & 12.6 & 13.5\end{array}$

$\begin{array}{lllllllllll}18.9 & 20 & 20.5 & 21.9 & 21.4 & 22.3 & 22.9 & 18.6 & 18.9 & 17.4 & 18.9\end{array}$

$\begin{array}{llllllllll}24.5 & 21.4 & 22.5 & 21.9 & 19.9 & 20.8 & 26.4 & 24.8 & 24.9 & 25.3\end{array}$

$\begin{array}{lllllllll}11 & 11.9 & 10.8 & 11.9 & 12.4 & 13 & 12.3 & 11.5 & 11\end{array}$ 
Table 1.1 (continued)

\begin{tabular}{lccccccccccc}
\hline & 1980 & 1981 & 1982 & 1983 & 1984 & 1985 & 1986 & 1987 & 1988 & 1989 & 1990 \\
\hline Ireland & 7.1 & 8 & 8.5 & 7.7 & 7.9 & 7.9 & 8.5 & 9 & 9.9 & 11.2 & 11 \\
Italy & & & & & & & & & 16.7 & 16.9 & 16.8 \\
Japan & & & & & 16.5 & 15.4 & 16.1 & 17.2 & 16.9 & 18.1 & 16.9 \\
Korea & & & & & & & & & & 0 & 0.3 \\
Luxembourg & 13.5 & 13.4 & 13.6 & 13.3 & 13.7 & 14.2 & 14.6 & 13.9 & 14.1 & 14.3 & 13.6 \\
Mexico & & & & & & & & & & & \\
Netherlands & 7.7 & 7.6 & 7.8 & 7.2 & 7.9 & 8.3 & 8.6 & 8.9 & 9.1 & 8.6 & 9.5 \\
New Zealand & 10.9 & 9.3 & 10.4 & 10.6 & 11.4 & 12.3 & 13.8 & 14 & 13.8 & 14 & 12.5 \\
Norway & 4.3 & 4.3 & 4.4 & 4.4 & 4.5 & 4.6 & 4.4 & 4.2 & 6 & 6.3 & 6.9 \\
Poland & & & & & & & & & & & \\
Portugal & 21.2 & & 22.6 & 22.5 & 21.9 & 30.1 & 29.4 & 33.9 & 27.5 & 28 & 23.7 \\
Spain & & & & & & & & & & & \\
Sweden & 16.8 & 16.6 & 17 & 15.6 & 15.1 & 15.7 & 14.9 & 14.9 & 17.5 & 16.7 & 16.2 \\
Switzerland & 5 & 4.7 & 5.2 & 5.4 & 5.1 & 5.4 & 5.6 & 5.9 & 5.1 & 6.3 & 6.4 \\
Turkey & & & & & & & & & & & \\
UK & & & & & 21.3 & 22.6 & 24.3 & 28.1 & & & 29.6 \\
USA & 9.7 & 9.6 & 10.5 & 10.3 & 10.5 & 10.5 & 10.7 & 10.6 & 11 & 11.1 & 10.8 \\
\hline
\end{tabular}

Source: OECD Health Data (2003).

several factors: (a) 'pure' variations in the price of existing products, (b) the appearance and spread of the consumption of new products with a higher than average price and a greater or lesser degree of therapeutic innovation, and (c) a shift in consumption from low-priced products to products with a higher price than those consumed previously, which may entail a greater or lesser degree of therapeutic innovation (shifts between different presentations, between different brands with the same active ingredient, and between different therapeutic subgroups).

The important question to answer is to what extent the increase in pharmaceutical prices involves an increase or a decrease (and of what magnitude) in the cost of health care. In other words, to what extent is the rise in pharmaceutical expenditure contributing to increase, maintain, or reduce the cost of obtaining an additional quality-adjusted life-year (QALY)? The first indispensable step towards eradicating the confusion that exists between pharmaceutical expenditure and cost of care is, in addition to choosing the right monetary magnitude, to avail ourselves of appropriate price indexes for drug consumption.

An accurate measure of the apparent causes of the evolution of pharmaceutical expenditure could be obtained by taking chain-linked Laspeyres price indexes for each therapeutic group with a suitable level of disaggrega-

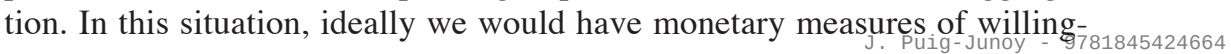




\begin{tabular}{cccccccccccc}
1991 & 1992 & 1993 & 1994 & 1995 & 1996 & 1997 & 1998 & 1999 & 2000 & 2001 & 2002 \\
\hline 10.6 & 11.1 & 10.7 & 11.1 & 11.3 & 11.7 & 11 & 11.4 & 11.8 & 11.6 & 12.7 & \\
15.6 & 14.6 & 13.2 & 11.1 & 11.1 & 11.3 & 11.4 & 12 & 12.7 & 13.4 & 16 & 15.5 \\
18.7 & 18 & 18.5 & 17.6 & 19.5 & 18.8 & 17.9 & 15.7 & 15.1 & 15.5 & 16.2 & \\
0.3 & 0.3 & 0.6 & 1.1 & 1.6 & 1.6 & 1.6 & 1.5 & 1.8 & 6.2 & & \\
13.7 & 14.2 & & 10.8 & 10.6 & 10 & 11.2 & 10.7 & 11 & 11.2 & & \\
& & & & & & & & 0 & 0.1 & 0.2 & \\
9.3 & 13.2 & 13.6 & 13.5 & 13.7 & 10.5 & 10.4 & 9.3 & 9.7 & 9.7 & 9.7 & \\
12.6 & 12.7 & 13.3 & 13.5 & 13.4 & 13 & 13.1 & & & & & \\
& & & & & & & & & & & \\
21 & 18.1 & 17.2 & 18.1 & 20.3 & 19.6 & 13.3 & 12.5 & 13 & 15.7 & 15.8 & \\
24.4 & 25.5 & 25 & 24.8 & 23.8 & 23.6 & 24 & & & & & \\
& & & & & & & & 28.9 & 31.4 & 31.5 & \\
16.9 & 17.2 & 17 & 17.8 & 19 & 19.6 & 20.9 & 21 & 21.6 & 21.8 & 22 & \\
7 & 7.9 & 8.8 & 10 & 10.4 & 11.6 & 9.6 & 10.9 & 11.4 & 11.4 & 10.9 & \\
& & & & 9.9 & 10 & 10.4 & 10.6 & 11 & 11.7 & 11.6 & \\
10.7 & 10.6 & 11 & 11.3 & 11.5 & 11.8 & 12.7 & & & & & \\
\end{tabular}

ness to pay for the improvement in quality of the main products, resulting from economic evaluations carried out using techniques such as contingent valuation, or by estimating the statistical value of life by means of hedonic prices. In this way we could determine the part of the price increases that are attributable to improvements in the quality of the products on the one hand and pure price rises on the other. The problems to solve in the construction of pharmaceutical price indexes are biases that are well known from the construction of inflation and welfare indexes: substitution bias, bias due to the appearance of new goods or services, and the consideration of changes in quality.

A number of empirical approaches have been put forward to quantify the price level and changes in prices of a treatment or a QALY: constructing price indexes (that is, learning to separate inflation from better inputs) for pharmaceuticals for a given disease taking into account the value of the innovation, changes in the structure of consumption, and so on; avoiding intertemporal comparisons of pharmaceutical cost per person, per stay, per illness, and so on, which add to the confusion between expenditure and the price of health; and developing measures of the monetary value of improvements in the quality of pharmaceutical innovations in order to establish the right relationship between spending and the price we are paying for additional QALYs (the true index of variation in the cost of health or life). 


\section{Table 1.2 Cost sharing in the health systems of western European countries}

\begin{tabular}{|c|c|c|c|}
\hline Country & First contact with the system & Referrals (within the system) & Pharmaceuticals \\
\hline Austria & $\begin{array}{l}\text { Does not affect } 80 \% \text { of the population. } \\
\text { A percentage rate of co-payment for health } \\
\text { care is applied to the rest, unless exempted } \\
\text { for reasons of low income }\end{array}$ & $\begin{array}{l}\text { Combination of co-payment and percentage } \\
\text { rate (with exemptions). The scheme of } \\
\text { direct payments by the patient is limited to } \\
\text { the first } 28 \text { days of hospitalization }\end{array}$ & $\begin{array}{l}\text { Co-payment for prescription drugs. Drugs not } \\
\text { prescribed by health professionals are excluded }\end{array}$ \\
\hline Belgium & $\begin{array}{l}\text { Wide range of co-payments and percentage } \\
\text { rates of cost sharing, with the exception of } \\
\text { the low-income bracket. Patients are entitled } \\
\text { to opt for an extra billing system }{ }^{\mathrm{a}}\end{array}$ & $\begin{array}{l}\text { Co-payment varying with the systems of } \\
\text { payment of the professionals. Benefits are } \\
\text { reduced after } 90 \text { days, less so for the low- } \\
\text { income bracket }\end{array}$ & $\begin{array}{l}\text { Co-payment and percentage rates of cost } \\
\text { sharing that range from } 0 \% \text { to } 85 \% \text { according to } \\
\text { the type of drug consumed. Pharmaceuticals } \\
\text { not included in the system's positive financing list } \\
\text { are not covered in any way }\end{array}$ \\
\hline Denmark & None & None & $\begin{array}{l}\text { Variable percentage rate of cost sharing }(0-50 \%) \\
\text { applied on the basis of drug reference prices (RP). } \\
\text { Drugs outside the MOH formulary are excluded } \\
\text { from the coverage of the system }\end{array}$ \\
\hline Finland & $\begin{array}{l}\text { None. A choice is made between: a prior } \\
\text { annual payment, a co-payment, and a }\end{array}$ & $\begin{array}{l}\text { Maximum payment levels for (daily) } \\
\text { hospital stays and for specialist visits }\end{array}$ & $\begin{array}{l}\text { Percentage rates of user sharing in } \\
\text { pharmaceutical costs }\end{array}$ \\
\hline
\end{tabular}
France
billing is permitted for certain categories of doctors

\section{Germany None. \\ Greece None, although extra billing is common practice among private doctors}

None. A choice is made between: a prior co-payment with a maximum in the user-shared bill for the annual cost. Varies

Percentage rates of cost sharing per diem, together with co-payments covering meals. Direct payments by the user are not applicable after the first 30 days Flat rate of co-payment for the first 14 days per year of hospitalization, after which there is no cost sharing of any sort None for hospital stays. Some schemes practice shared financing through user cost-sharing rates for diagnostic services
Mostly subject to percentage rates of cost sharing. There is a positive list of

pharmaceuticals with public coverage

Variable co-payment. RP system. No coverage is applied to those pharmaceuticals on public financing negative lists

Percentage rates of user sharing in pharmaceutical costs 
Iceland Co-payments, with higher rates for visits outside normal working hours. Larger co-payments for house calls. A maximum is set for the financial participation of the user

Ireland

None for category I of the population (represented 37\% in 1987). The participation is $100 \%$ for the rest of the population unless they take out health insurance against it. An annual deductible is applied to insured groups which also acts as a maximum level of user participation

Italy None

\section{Luxembourg Percentage rates of user sharing in the cost of services}

Netherlands None for public insurance, but varies in the case of private insurance

Norway Cost sharing, with a maximum annual

Portugal contribution for all services as a whole Cost sharing

None
None for hospital stays. Combination of co-payment and percentage rate of cost sharing for specialist care and out-patient visits. Co-payment in diagnostic services. A maximum is set for the financial participation of the user

None for category I in public hospitals. For the rest, co-payments are applied for the first out-patient visit per episode, and there is a per diem co-payment for the first 10 days of hospitalization per year. Insurers buy free care for both public and private hospitals

None for in-patient care. Cost sharing was introduced in 1990 for public hospitals with regard to diagnostic procedures, hospital visits and spa treatments

Inflation-linked per diem co-payments

None for public insurance, but varies in the case of private insurance

None for in-patient care. Cost sharing for diagnostic services

Cost sharing

None
Combination of daily deductibles per prescription and percentage rates of cost sharing up to a maximum level. Some medicines are completely free, while others are excluded from public coverage

None for population category I. Deductibles are applied to the rest of the population which also act as monthly maximum levels of user participation. Pharmaceuticals included in the negative list of public funding are not covered

Deductibles are only applied for medicines that are considered essential. Most of the rest are financed through a combination of deductables and percentage rates of cost sharing. Some pharmaceuticals are excluded from public coverage

Percentage rates of cost sharing, except in the case of 'special diseases'. Medicines are free during hospitalization

RP system, with the exclusion of some

pharmaceuticals

RP system for medicines that are considered essential

Two percentage cost sharing rates, depending on the type of pharmaceuticals involved. Some pharmaceuticals are free, while others are excluded from public coverage

Percentage rates of sharing in the cost of pharmaceutical consumption. Positive list of pharmaceuticals with public coverage 


\section{Table 1.2 (continued)}

\begin{tabular}{|c|c|c|c|}
\hline Country & First contact with the system & Referrals (within the system) & Pharmaceuticals \\
\hline Sweden & $\begin{array}{l}\text { Co-payment, with maximum levels of sharing } \\
\text { in health service bills, with the exception of } \\
\text { hospital in-patient bills }\end{array}$ & $\begin{array}{l}\text { Per diem co-payment for in-patient services. } \\
\text { Co-payment for therapeutic referrals }\end{array}$ & $\begin{array}{l}\text { Co-payment for the first drug prescribed, with } \\
\text { significantly lower co-payments for subsequent } \\
\text { prescriptions. RP system for medicines with } \\
\text { 'generic' equivalents }\end{array}$ \\
\hline Switzerland & $\begin{array}{l}\text { Combination of annual deductibles and } \\
\text { percentage cost-sharing rates }\end{array}$ & Per diem co-payments for hospitalization & $\begin{array}{l}\text { User sharing in drug consumption costs, which } \\
\text { varies between different health insurance schemes. } \\
\text { Negative lists of medicines exclude consumption } \\
\text { from public coverage }\end{array}$ \\
\hline Turkey & $\begin{array}{l}\text { Mostly private providers who apply 'payment } \\
\text { per act' (FFS) schemes in their bills }\end{array}$ & $\begin{array}{l}\text { Social health insurance covers the totality of } \\
\text { costs, although specific rates are applied to } \\
\text { uninsured groups }\end{array}$ & $\begin{array}{l}\text { All social health insurance schemes apply } \\
\text { percentage rates of user participation for medicines } \\
\text { (in out-patient visits) }\end{array}$ \\
\hline UK & None & None, except for hospital rest beds & $\begin{array}{l}\text { Co-payments, although } 83 \% \text { of prescriptions are } \\
\text { exempt. Negative lists of medicines exclude NHS } \\
\text { coverage }\end{array}$ \\
\hline
\end{tabular}

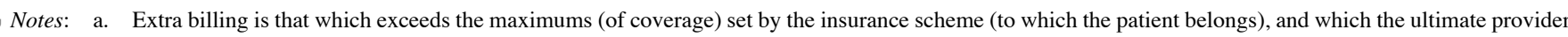
of the services charges directly to the patient.

Source: López-Casasnovas, G., V. Ortún and C. Murillo (1999), El sistema sanitario español: informe de una década, Bilbao: Fundación BBV. 


\section{THE CONTENTS OF THIS BOOK}

This book consists of a series of works that evaluate various aspects related to the public financing of pharmaceuticals. In all health systems with majority public funding, the financing of pharmaceuticals constitutes one of the key factors in reform policies and health cost containment measures. This importance of pharmaceutical spending can be explained by both its relative size (its share within health expenditure as a whole), and its rapid growth, which is closely related to the constant incorporation of therapeutic innovations.

The credibility of the commitment to maintain and even improve the public funding of medicines in the short and long term renders it necessary to take measures aimed at reducing the imperfection and inequality of users'/voters' information about the fact that not all pharmaceuticals are equally effective or necessary, and that there is no worse enemy for the public provision of pharmaceuticals (and indeed one's state of health) than the illusion that it is possible to indiscriminately continue to provide any drug to anyone regardless of its effectiveness and cost.

An efficient pharmaceutical policy should go beyond the partial regulation of drugs, industry and prescribers. Its makers should learn how to combine these instruments, by explicitly recognizing the conflicts of interests that are at work in the sector. This involves making the effort to find the right dose of each regulatory measure, to underline that public financing must be based on cost-effectiveness criteria, and that these criteria must be applied in such a way as to create a stable framework for industry and thus encourage innovation.

The contributions included in this book seek to provide economic keys for a better understanding of both the dynamics of public pharmaceutical spending and the effects of public policies in this area. We see these economic keys as indispensable for overcoming clichés and truisms and building the debate on public pharmaceutical funding on theoretical and empirical findings. In this respect, the public policies implemented in recent years with a view to rationalizing and containing the growth rate of expenditure should in no way be regarded as useless or ineffective. However, we find that these measures can only be effective if coordinated and integrated policies are adopted that take into consideration the overall effect on the role of pharmaceuticals, and if the best knowledge available is taken as the point of reference. The effectiveness of partial measures depends on the integration and coordination of the incentives present on the various fronts of pharmaceutical policy. One key factor for an integrated pharmaceutical policy is to be found in action on the economic and non-economic incentives of prescribers (self-regulation, controls by health authorities, budgets, prescription guidelines, information and pharmacological counselling).

The first group of contributions focus on regulation and competition in the 9781845424664 
Table 1.3 Pharmaceutical expenditure as a percentage of total health expenditure

\begin{tabular}{|c|c|c|c|c|c|c|c|c|c|c|}
\hline Years & 1960 & 1961 & 1962 & 1963 & 1964 & 1965 & 1966 & 1967 & 1968 & 1969 \\
\hline $\begin{array}{l}\text { Australia } \\
\text { Austria } \\
\text { Belgium }\end{array}$ & 22.6 & & & 22.2 & & & 21.6 & & & 17.8 \\
\hline $\begin{array}{l}\text { Canada } \\
\text { Czech Rep. } \\
\text { Denmark }\end{array}$ & 12.9 & 12 & 11.7 & 11.7 & 11.7 & 12.1 & 11.7 & 11.7 & 11.4 & 11.4 \\
\hline $\begin{array}{l}\text { Finland } \\
\text { France } \\
\text { Germany } \\
\text { Greece } \\
\text { Hungary }\end{array}$ & 17.1 & 17.1 & 15.8 & 15.3 & 14.8 & 14.8 & 14 & 13.4 & 13.1 & 12.5 \\
\hline $\begin{array}{l}\text { Iceland } \\
\text { Ireland } \\
\text { Italy } \\
\text { Japan } \\
\text { Korea } \\
\text { Luxembourg } \\
\text { Mexico } \\
\text { Netherlands } \\
\text { New Zealand }\end{array}$ & 18.5 & 19.2 & 19.9 & 18.4 & 18.2 & 17.7 & 16.3 & 17.4 & 16.7 & 18.9 \\
\hline $\begin{array}{l}\text { Norway } \\
\text { Poland } \\
\text { Portugal } \\
\text { Spain } \\
\text { Sweden } \\
\text { Switzerland } \\
\text { Turkey } \\
\text { UK }\end{array}$ & & & 9.7 & 10 & 9.5 & 8.9 & 8.7 & 8.9 & 8.7 & 8.6 \\
\hline USA & & & & 12.9 & 13.5 & 15.8 & 15.1 & 14.9 & 14.6 & 15.2 \\
\hline Years & 1980 & 1981 & 1982 & 1983 & 1984 & 1985 & 1986 & 1989 & 1990 & 1991 \\
\hline $\begin{array}{l}\text { Australia } \\
\text { Austria }\end{array}$ & 8 & 8.1 & 8 & 8.3 & 8.1 & 8.1 & 8.1 & 8.1 & 8.4 & 8.8 \\
\hline Belgium & 17.4 & 16 & 15.4 & 15.6 & 15 & 15.7 & 15.7 & 16 & 16.5 & 16.2 \\
\hline $\begin{array}{l}\text { Canada } \\
\text { Czech Rep. }\end{array}$ & 8.5 & 8.9 & 8.6 & 8.7 & 9.1 & 9.6 & 10.3 & 10.6 & 11 & 11.2 \\
\hline Denmark & 6 & 5.9 & 6 & 6.2 & 6.4 & 6.6 & 7 & 6.7 & 7.1 & 6.8 \\
\hline $\begin{array}{l}\text { Finland } \\
\text { France }\end{array}$ & 10.7 & 10.3 & 9.8 & 10 & 10 & 9.7 & 9.6 & 9.6 & 9.5 & 9.4 \\
\hline $\begin{array}{l}\text { Germany } \\
\text { Greece } \\
\text { Hungary }\end{array}$ & $\begin{array}{l}13.4 \\
18.8\end{array}$ & 13.5 & 13.4 & 13.7 & 13.8 & 13.8 & 13.9 & $\begin{array}{l}14.1 \\
13.3\end{array}$ & $\begin{array}{l}14.2 \\
14.8\end{array}$ & $\begin{array}{l}14.3 \\
13.6\end{array}$ \\
\hline Iceland & 15.9 & 14.7 & 15.2 & 17.4 & $\begin{array}{r}16.5 \\
\text { Don }\end{array}$ & $\begin{array}{r}16.6 \\
\text { Loaded }\end{array}$ & $\begin{array}{l}15.8 \\
\text { from Pu }\end{array}$ & $\begin{array}{r}14.7 \\
\mathrm{~J} . \\
\text { actor }\end{array}$ & $\begin{array}{l}14.2 \\
\text { ig- Jun } \\
\text { at } 04 /\end{array}$ & $\begin{array}{l}14.8 \\
-9781845424664 \\
/ 2023 \text { 09:55:28AM } \\
\text { via free access }\end{array}$ \\
\hline
\end{tabular}




$\begin{array}{rrrrrrrrrr}1970 & 1971 & 1972 & 1973 & 1974 & 1975 & 1976 & 1977 & 1978 & 1979 \\ & 13.7 & 12.9 & 13 & 12.6 & 9.8 & 9.1 & 8.5 & 8.5 & 7.7 \\ 28.1 & 28.3 & 27.6 & 27.5 & 26.8 & 21.9 & 18.9 & 18.3 & 17.8 & 17.4 \\ 11.3 & 10.8 & 10.4 & 10.4 & 9.5 & 8.9 & 8.6 & 8.6 & 8.5 & 8.7 \\ & & & & & & & & & \\ 12.6 & 13.6 & 13.5 & 12.8 & 12.4 & 11.9 & 12 & 11.9 & 11.9 & 11.4 \\ 16.2 & 15.5 & 15.2 & 14.6 & 14.2 & 13.7 & 13.7 & 13.4 & 13.4 & 13.4 \\ 25.5 & & & & & & & & & \\ 17.1 & 17.3 & 17.8 & 16.6 & 13.8 & 16.2 & 14.8 & 14.6 & 14.5 & 13.5 \\ 22.2 & & 18.8 & 17.8 & 14.9 & 13.8 & 13.5 & 13.4 & 12.9 & 12.3\end{array}$

$\begin{array}{llllllllll}19.7 & 19.3 & 18.8 & 19.6 & 19 & 16.6 & 16.4 & 15.3 & 15.2 & 15\end{array}$

$\begin{array}{llllllll}10.3 & 10.3 & 9.7 & 9.3 & 9.1 & 8.7 & 8.5 & 8.3\end{array}$

$\begin{array}{lll}11.4 & 10.6 & \end{array}$

$\begin{array}{llllllllll}7.8 & 7.3 & 6.5 & 6.4 & 6.5 & 6.4 & 6.1 & 5.7 & 5 & 5.3\end{array}$

$\begin{array}{llll}13.4 & 19.8 & 22.9 & 23.7\end{array}$

$\begin{array}{llllllllll}6.6 & 6.9 & 7.6 & 8.5 & 8.3 & 7.9 & 7.5 & 7.2 & 7 & 6.9\end{array}$

$\begin{array}{llllllllll}14.7 & 14.8 & 14.4 & 13.8 & 13.9 & 11.8 & 12.3 & 12.8 & 13 & 12.9\end{array}$

$\begin{array}{llllllllll}1992 & 1993 & 1994 & 1995 & 1996 & 1997 & 1998 & 1999 & 2000 & 2001\end{array}$

$\begin{array}{llllllllll}9 & 9.5 & 9.9 & 10.4 & 11 & 11.2 & 11.5 & 11.7 & 11.9 & 12.4\end{array}$

$\begin{array}{lllllll} & 11.1 & 11.2 & 13.1 & 14 & 14.5\end{array}$

$\begin{array}{llllllllll}15.5 & 15.6 & 16.3 & 17.4 & 17.5 & 16.5 & 15.8 & 16.5 & & \\ 11.5 & 11.8 & 12.4 & 13 & 13.1 & 13.8 & 14 & 14.7 & 15.2 & 15.3\end{array}$

$\begin{array}{llllllllll}21 & 18.4 & 21.1 & 19.4 & 24.7 & 25.6 & 25.5 & 25.3 & 25.5 & 22.7\end{array}$

$\begin{array}{llllllllll}7.5 & 8 & 7.9 & 8.5 & 8.8 & 9.1 & 8.9 & 9 & 9 & 8.7\end{array}$

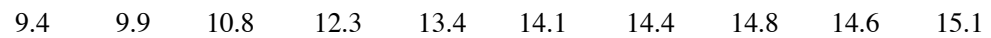

$\begin{array}{llllllllll}16.9 & 17.2 & 17.1 & 17.5 & 17.4 & 17.6 & 17.6 & 18 & 18.6 & 19.5\end{array}$

$\begin{array}{lllllllll}14.3 & 14.7 & 13.2 & 12.9 & 12.7 & 12.8 & 12.9 & 13.4 & 13.5\end{array}$

$\begin{array}{llllllllll}14.3 & 16.3 & 17 & 16.6 & 16.1 & 15.7 & 16.1 & 16.2 & 13.9 & 13.8\end{array}$

$\begin{array}{lllllllll}27.6 & 26.5 & 28.4 & 28 & 25 & 26 & 25.9 & & \\ 14.2 & 14.9 & 14.3 & 15 & 15.5 & 16.5 & 16.1 & 15.3 & 14.5\end{array}$

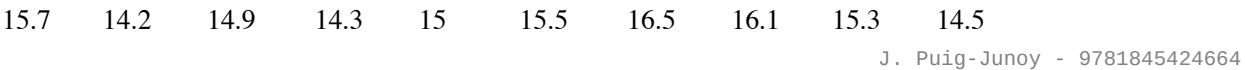


Table 1.3 (continued)

\begin{tabular}{lcccccccccc}
\hline Years & 1980 & 1981 & 1982 & 1983 & 1984 & 1985 & 1986 & 1989 & 1990 & 1991 \\
\hline Ireland & 10.9 & 9.7 & 9.8 & 9.4 & 9.9 & 9.9 & 10.4 & 10.8 & 11.4 & 12.3 \\
Italy & & & & & & & & & 21.1 & 21.3 \\
Japan & 21.2 & & & & 19.5 & 18 & 18.9 & 20.3 & 20.6 & 22.3 \\
Korea & & & & & & 28.7 & 29.5 & 31.1 & 29.4 & 29.4 \\
Luxembourg & 14.5 & 14.4 & 14 & 13.8 & 14.2 & 14.7 & 15.2 & 14.9 & 15.5 & 15.7 \\
Mexico & & & & & & & & & & \\
Netherlands & 8 & 8 & 8.2 & 8.2 & 8.9 & 9.3 & 9.6 & 10 & 9.9 & 9.3 \\
New Zealand & 11.9 & 10.8 & 11.4 & 12 & 12.4 & 13.3 & 14.5 & 14.7 & 14.2 & 14.3 \\
Norway & 8.7 & 8.9 & 9.1 & 9 & 9.1 & 9.1 & 9 & 8.6 & 6.4 & 6.7 \\
Poland & & & & & & & & & & \\
Portugal & 19.9 & 18.2 & 18 & 19.2 & 19.9 & 25.4 & 22.5 & 24.9 & 22.9 & 23.9 \\
Spain & 21.0 & 20.6 & 21.2 & 20.0 & 18.6 & 20.3 & 19.0 & 18.1 & 17.8 & 18.3 \\
Sweden & 21 & 20.6 & 21.2 & 20 & 18.6 & 20.3 & 19 & 18.7 & 17.8 & 18.1 \\
Switzerland & 6.5 & 6.5 & 6.8 & 6.9 & 6.6 & 7 & 7.2 & 7.5 & 6.9 & 7.9 \\
Turkey & & & & & & 11.3 & 11.8 & 10 & 10.4 & 10 \\
UK & & 10.2 & 11.6 & 10.9 & 10.6 & 13.2 & 11.8 & 12.6 & & \\
USA & 12.8 & 12.7 & 13.6 & 13.5 & 14.3 & 14.1 & 14.1 & 13.6 & 13.8 & 13.8 \\
\hline
\end{tabular}

Source: OECD Health Data (2003).

pharmaceutical sector as a whole, and its effects on the introduction of innovations and the level of pharmaceutical prices.

In Chapter 2, Pompeu Fabra University lecturer P. Ibern Regàs offers an analysis of the advantages and the limitations of the financing of innovation in the pharmaceutical sector based on protection through patents. The author observes that, although patents have indisputably contributed to the development of innovation (with private financing of a public good), economic theory yields results that cast doubt on the suitability of this instrument when applied uncritically throughout the whole pharmaceutical sector. Several studies have shown that the marginal extension of patents to developing countries, when an innovation has already become widespread in the major pharmaceutical markets, can result in welfare losses. The author suggests that it would be advisable to revise the situation of patents as a mechanism for promoting innovation when there are alternative proposals that are firmly founded on theory, along the lines of the acquisition of patents by governments.

In the sphere of price regulation, professor J. Puig-Junoy of Pompeu Fabra University analyses in Chapter 3 the price regulation systems used in the OECD countries and their main effects. Theoretical justifications for price regulation in markets of prescription drugs whose patent has expired are scarce, and therefore price regulation in these cases is generally speaking unjustified. The author argues that individual price regulation systems for each 


\begin{tabular}{cccccccccc}
1992 & 1993 & 1994 & 1995 & 1996 & 1997 & 1998 & 1999 & 2000 & 2001 \\
\hline 12.2 & 11.6 & 11.1 & 10.7 & 10.6 & 10.4 & 10.5 & 10.2 & 10.4 & 10.5 \\
21.2 & 20.4 & 20.4 & 19.9 & 19.9 & 20.9 & 21.1 & 21.3 & 21.8 & 22.3 \\
21.4 & 22.9 & 22 & 22.3 & 21.1 & 22.4 & 21.8 & 20.8 & 18.9 & 18.1 \\
25.7 & 26.8 & 25 & 24.3 & 22.7 & 21.9 & 19.8 & 17 & 13.8 & 13.9 \\
14.9 & 15 & & & 12.2 & 12 & 11.5 & 12.6 & 12.3 & 12.1 \\
& & & & & & & & & 18.6 \\
9.6 & 9.6 & 10.5 & 11 & 10.9 & 11 & 11 & 11 & 9.7 & 10 \\
13.8 & 14.1 & 14.2 & 14.9 & 15.8 & 14.8 & 14.5 & 14.4 & & \\
7.2 & 7.3 & 7.5 & 9.6 & 8.8 & 9 & 9.1 & 9.2 & & \\
& & & & & & & & & \\
24.9 & 24.3 & 24.7 & 25.6 & 25.2 & 23.2 & 23.6 & 23.5 & 22.8 & \\
18.6 & 18.6 & 18.5 & 19.6 & 20.0 & 20.7 & & & & 34 \\
17.8 & & & & & & & & & \\
8 & 8.7 & 9.7 & 10.7 & 11.8 & 12.3 & 13.6 & 12.4 & 13.6 & 13.9 \\
10.2 & 9.8 & 9.4 & 9.7 & 9.8 & 10 & 10 & 10.3 & 10.2 & 10.5 \\
20.5 & & & & 31.6 & & & & & \\
13.5 & 13.8 & 14.2 & 14.8 & 15.1 & 15.3 & 15.6 & 15.8 & &
\end{tabular}

product are ineffective as a system for controlling the profits of pharmaceutical companies. The rate of return regulation system that operates in the UK gives firms a certain amount of leeway in the pricing of individual products, but it still suffers from the inefficiency problems attributed to this public service regulation system by economic theory.

The price intervention system that has operated in Spain since 1991 is based on the fixing by the health authorities of the price cap for each product, calculated according to what is called its 'cost'. The application of this system, together with the restrictive criteria used in price revisions, has brought about a situation in which the relative price level of pharmaceuticals that have been on the market for some time would appear to be lower in Spain than in other countries, although this trend is being offset by the faster rate at which new and more expensive products are being introduced onto the market. This situation has led the health authorities to apply other measures on the supply side, such as agreements with Farmaindustria and reference pricing.

The present Spanish system of price control is inefficient, as it provides notable negative incentives for pharmaceutical consumption and expenditure; it would be desirable to replace it with a more flexible system such as an overall profit control system, or a combination of price-cap regulation and rate of return regulation.

In Chapter 4, University of Barcelona lecturers J.R. Borrell Arqué, A. 
Costas Comesaña and R. Nonell Torres look at the extent to which pharmaceuticals are withstanding competition from therapeutic substitutes and generics, and how necessary price regulation is. This chapter provides empirical evidence on competition between rival pharmaceuticals in England and Spain, and shows the number of pharmaceuticals on the market, the position of dominance occupied by products in relation to their substitutes, and the prescription concentration at various levels of therapeutic and generic differentiation. The authors conclude that the different national regulations have shaped markets that differ greatly in the type of competition between substitute drugs. Generic competition between products/drugs containing the same therapeutic substance is seen to be keener in England, whereas therapeutic competition between products containing different substances is more intense in Spain.

In the same sphere, in Chapter 5, University of Barcelona lecturers J. Rovira Forns and J. Darbà Coll analyse mechanisms designed to encourage price competition in the pharmaceutical market and their effects on efficiency and welfare. The authors first study the supply factors that restrict competition (patents, brands, registration and marketing authorization) and also the demand factors (absence of incentives). They then go on to conclude that price discrimination between market segments may provide a solution by bringing together the interests of the various economic agents involved. From this point of view, the establishment of a single price internationally for a product under patent is not the optimal solution, and welfare gains can be generated by means of price differentiation in each market (Ramsey prices). Nevertheless, both the phenomenon of parallel imports and national price regulation on the basis of the observed price in other countries tend to work for the smoothing of prices.

The second series of contributions focus on the analysis of the application and effectiveness of the main instruments public financing agencies use to regulate pharmaceutical expenditure, on both the demand side and the supply side.

Reference pricing as a mechanism for pharmaceutical reimbursement by public insurers is the subject of Chapter 6, by professors G. López-Casasnovas and J. Puig-Junoy of Pompeu Fabra University. A reference pricing system operates by classifying pharmaceuticals into equivalent groups, and fixes a maximum reimbursement level for drugs that are classified within the same group and an (avoidable) co-payment equivalent to the difference between the retail price and the maximum reimbursable level. The application of the reference pricing system in Spain is limited to bio-equivalent drugs, in which area very little doubt can be cast on the justification and effectiveness of this mechanism.

The greatest effectiveness of reference pricing as a public spending control mechanism is achieved in health care environments in which the problem of ${ }_{\mathrm{J}}$ Pug-Junoy 9781845424664 
pharmaceutical expenditure lies in high unit prices and the prescribed product is easily substituted by the pharmacist. Reference pricing can be useful for encouraging price competition in products whose patent has expired. It can result in a larger market share for generics and a drop in prices for brand products that are unprotected by patents.

Reference pricing was not introduced in Spain until December 2000. The fact that it is applied exclusively to bio-equivalent products leads, in the opinion of the authors, to the assumption that its effect on expenditure is limited, as a major market share is acquired by recently introduced drugs. The level at which the reference price is fixed is an important factor. For non-patented products, price competition should push the price towards the marginal cost, and therefore a reference price that is clearly higher than the cheapest generic could actually become a barrier to price competition in this case.

Empirical evidence suggests that the price paid by the patient should not be given a predominant role in the regulation of pharmaceutical expenditure. Available studies on the effects of co-payments indicate that they are more useful for increasing the financing of the user in the cost of the service than for reducing consumption, and therefore the reduction is not very great, as the demand is fairly inelastic. Furthermore, the application of co-payments with exemptions in order to attenuate the negative effects on equity is generally complex and costly.

In Chapter 7, professor B. González López-Valcárcel of the University of Las Palmas de Gran Canaria analyses the participation of the insuree in the payment of the price of the pharmaceutical. In spite of the widespread application of pharmaceutical co-payment in European health systems, the author observes that this mechanism does not appear to have been very effective in cost containment. Co-payments represent a way of making the user share the burden of the cost rather than an essential source of income for the public system. Theory and comparative experience of the system alike indicate that the indiscriminate application of co-payments is a source of inequalities, and that in any event its effects on consumption depend largely on prescriber incentives. For this reason the author recommends that co-payments should not be uniform for different population groups, and that they should not be applied in isolation, as their effectiveness is enhanced in combination with other instruments.

In Chapter 8, professor J.L. Pinto Prades of Pompeu Fabra University and X. Badía Llach of the Health Outcomes Research Unit at Santa Creu i Sant Pau Hospital take a look at the potential contribution of economic evaluation to the regulation and control of public spending on pharmaceuticals. The authors focus on observing how economic evaluation can be used in pharmaceutical policy. To this end, they distinguish and analyse the potential this instrument has in six distinct areas: the approval of pharmaceuticals by health 
authorities, drug prices, financing, medical treatment guidelines, reimbursement and patent policy. The authors' thesis is that economic evaluation can help to design more efficient policies in all these areas of the pharmaceutical regulation process.

In Chapter 9, lecturers V. Ortún Rubio of Pompeu Fabra University and L. Cabiedes Miragaya of the University of Oviedo address the subject of measures intended as a way of influencing prescriber decisions. The authors place special emphasis on analysing prescriber incentive policies, distinguishing between incentives of a financial nature (both coercive and non-coercive) and nonfinancial incentives (information, training, treatment protocols, monitoring of prescription practices, cost-effectiveness guidelines, interaction with other professionals, pressure from patients and so on). The authors advocate incentive policies based on a combination of financial and non-financial incentives.

The third group of contributions consists of the two final chapters that focus specifically on the present situation and the outlook for the future of pharmaceutical expenditure within the Spanish health system.

In Chapter 10, professor G. López-Casasnovas of Pompeu Fabra University provides evidence of expenditure behaviour and the evolution of the public financing of pharmaceuticals in the context of Spanish public health expenditure. Empirical evidence based on simple data may lead to excessively direct and contradictory conclusions as to the situation of Spanish pharmaceutical spending. Such would be the case of the figures for the share of health expenditure devoted to spending on pharmaceuticals (the Spanish figure is above the average for Western countries), whereas expenditure per capita is below the EU average. The author notes that although pharmaceutical expenditure has been subjected to all possible containment measures, to date no decrease has been forthcoming in Spanish pharmaceutical spending; indeed, quite the contrary. In López-Casasnovas' opinion, the sector requires the adoption of a stable 'legal' framework with a broad consensus, in order to lay down guidelines for the public financing of pharmaceutical expenditure in the mid-term.

Lastly, F. Lobo of Carlos III University, M. Cabañas Sáenz and R. González Pérez present in Chapter 11 the results of a review of the research done by Spanish economists on the economics of pharmaceuticals since 1980.

\section{ACKNOWLEDGEMENTS}

This book is a revised and updated translation of a previously published volume entitled Análisis económico de la financiación publica de medicamentos, published in Spanish in 2002 by Masson S.A. Barcelona, Spain.

This book has been translated into English by Tobias Willett, and revised by the authors. 